\title{
EN EL CAMINO DE LA JUSTICIA AMBIENTAL: ESTABLECIENDO VÍNCULOS ENTRE MEDIO AMBIENTE Y JUSTICIA SOCIAL
}

\section{IN THE WAY OF ENVIRONMENTAL JUSTICE: CREATING LINKS BETWEEN ENVIRONMENT AND SOCIAL JUSTICE}

\section{Alberto Gutiérrez Arguedas*}

\begin{abstract}
RESUMEN
El artículo discute los principios de justicia ambiental, un enfoque y práctica que trabaja reconociendo a los seres humanos en su inserción permanente en el ambiente. Como tal, su comprensión acerca de los problemas ambientales pasa primero por la comprensión de las desigualdades sociales y políticas que los producen. Asimismo, se analizan las diferentes corrientes $y$ disputas que existen dentro del campo ambiental y procura vincular el estudio de los conflictos ambientales con el de los territorios, así como, las diversas territorialidades que en ellos coexisten.
\end{abstract}

PALABRAS CLAVE: MEDIO AMBIENTE * JUSTICIA * CONFLICTOS * DETERIORO AMBIENTAL * TERRITORIALIDADES

\section{ABSTRACT}

This article discusses the principles of environmental justice, an approach and practice that works recognizing humans in their permanent placement in the environment. As such, its understanding of environmental issues first passes through the understanding of the social and political inequalities that produce them. Also, it analyzes the different schools of thought and disputes that exist within the environmental field. Furthermore, it seeks to link the study of environmental conflicts to the study of territories and the various territorialities that coexist within them.

KEYWORDS: ENVIRONMENT * JUSTICE * CONFLICTS * ENVIRONMENTAL DEGRADATION * TERRITORIALITIES

Escuela de Geografía de la Universidad de Costa Rica (UCR).

alguar48@gmail.com 


\section{INTRODUCCIÓN}

En las últimas décadas, el tema ambiental ha adquirido mayor visibilidad y se ha constituido como obligatorio en la agenda política. En realidad lo que hoy se conoce como ambiental ha estado presente en todo momento de la historia humana; la verdadera novedad desde el surgimiento del ambientalismo y el debate ambiental propiamente dicho, en la década de 1960, ha sido la incorporación del ambiente como una categoría estratégica y central para discutir los estilos de vida y la estructura social en un planeta visto por primera vez como limitado (Loureiro, 2012). Como es de esperar, son muchas y muy diferentes las visiones y posicionamientos políticos que existen al respecto, los cuales configuran una trama y un campo de fuerzas complejo y muchas veces contradictorio.

El presente artículo tiene como objetivo aportar algunos elementos para tal debate desde la óptica de la Justicia Ambiental. Esta se ha constituido como un paradigma desde el cual múltiples movimientos sociales han pautado sus reivindicaciones y estrategias, así como no acepta la separación entre sociedad y ambiente, buscando así establecer un vínculo entre problemas ambientales e injusticia social. $\mathrm{El}$ abordaje generalista de este artículo no pretende invisibilizar las especificidades de cada situación, cada lugar y cada comunidad, sino todo lo contrario, complementarlas y enriquecerlas. Es importante recordar que cada caso es único y no existen recetas universalizantes; sin embargo, es posible encontrar similitudes entre estos. Se pretende descubrir y comprender esos vínculos en común que unen los diferentes esfuerzos por justicia ambiental.

El trabajo está organizado en tres partes. En la primera parte, se presenta el contexto del cual surge la lucha por justicia ambiental, el cual ha abierto nuevos caminos de reflexión/ acción y ha permitido la articulación, por ejemplo, de algunos sectores dentro de la academia con los movimientos sociales en diversas partes del mundo. En la segunda parte, se discute sobre las contradicciones $y$ disputas que existen dentro del campo ambiental, donde los principios de justicia ambiental contrastan con otras visiones sobre el manejo del ambiente, entre ellas, algunas que inclusive reproducen las injusticias ambientales. Finalmente, se busca establecer un puente conceptual entre justicia ambiental, conflictos ambientales $y$ territorialidades, ya que una transformación en las formas de relacionarse con/en el medio ambiente implica una transformación en las formas en cómo se organiza el poder y esto a su vez considera, otras configuraciones territoriales.

\section{JUSTICIA AMBIENTAL: ¿QUÉ ES?}

La lucha por justicia ambiental implica el reconocimiento y la denuncia de una situación de injusticia ambiental, evidenciada, entre otras cosas, por una distribución geográfica desigual de los provechos y los desechos (PortoGonçalves, 2011a). Esta afirmación, que puede parecer obvia, en realidad contradice un discurso que es bastante difundido y aceptado en el debate ambiental, según el cual, por un lado, la "crisis ambiental" es un problema "global" que afecta por igual a todo el planeta y la humanidad, $y$ por otro, sugiere que es la humanidad como un todo, la causante de tal crisis; es decir, no se cuestiona por el grado diferenciado de responsabilidad que cada grupo, clase social y región tiene en tales procesos socio-ambientales, ni tampoco por el hecho de que hay grupos que sufren desproporcionadamente por los daños ambientales, mientras que otros parecen casi no verse afectados por estos.

Por esta razón, surge la interrogante ¿qué hay por detrás del encubrimiento de estas diferencias y desigualdades? Así, el reconocimiento de la injusticia ambiental parte del hecho de que la cuestión ambiental está por dentro de las relaciones sociales, económicas $y$ políticas (que son contradictorias y asimétricas), la cual tiene que ser analizada y enfrentada en esos términos.

Es importante hacer una distinción entre las diferentes formas a través de las cuales las sociedades humanas se relacionan socialmente entre sí y con la naturaleza, así como, los diferentes grados de presión que generan sobre el ambiente $y$ sus recursos. Cualquier grupo necesita transformar las condiciones naturales de sus lugares de habitación para sustentar su 
vida $y$ vivir colectivamente. Todos necesitan producir y consumir; el problema no reside ahí, sino de qué forma, en qué ritmo y con qué fin se hace eso.

En defensa de grandes obras y proyectos desarrollistas con una influencia pesada sobre el ambiente y las poblaciones locales, se escucha con frecuencia que de todas formas cualquier actividad humana genera una presión sobre la naturaleza (la destrucción comenzó cuando el primer Homo sapiens derribó el primer árbol, afirman algunos). Esa argumentación es como mínimo, insuficiente, además de confusa y parece querer legitimar una ideología $y$ un proyecto económico a toda costa.

La cuestión ambiental comienza a ser un problema, no con el surgimiento de lo humano, sino desde el momento en que un modo específico de producción, con alta capacidad de transformar/movilizar materia/energía, busca imponerse por todo el globo, estableciendo como prioridad la acumulación de riquezas y no la satisfacción de necesidades básicas (Loureiro, 2012).

Según Ascelrad, Mello y Bezerra (2009), la injusticia ambiental se manifiesta principalmente en dos aspectos: desigualdad en la protección ambiental y desigualdad en el acceso a los recursos ambientales. El primero de esos aspectos hace referencia al hecho de que son los sectores más empobrecidos de la sociedad, así como, las poblaciones tradicionales (indígenas, campesinos, afrodescendientes, pescadores, etc.), los que sufren más intensamente las consecuencias de la degradación ambiental, tanto en contextos urbanos como rurales. Estos autores afirman:

La protección ambiental es desigual cuando la implementación de políticas ambientales —o la omisión de tales políticas ante la acción de las fuerzas del mercado-genera riesgos ambientales desproporcionados, intencionales o no intencionales, para los más carentes de recursos financieros y políticos: los más pobres, los habitantes de áreas desvalorizadas $y$ etnias marginalizadas. Si hay diferencia en los grados de exposición de las [diferentes] poblaciones a los males ambientales, eso no se debe a ninguna condición natural, determinación geográfica o casualidad histórica, sino a procesos sociales y políticos que distribuyen de forma desigual la protección ambiental (2009: 73).

El segundo aspecto tiene que ver con el acceso desigual a los recursos naturales, que se manifiesta tanto en la esfera de producción como la de consumo. La imposición de un modelo de desarrollo productivista y mercantil, a través de grandes obras que demandan un gran volumen de recursos, muchas veces desestabiliza $y$ agrede las formas tradicionales $y$ no-capitalistas de apropiación de los recursos naturales, alterando el paisaje, el territorio $y$ a las poblaciones locales. Se mencionan como ejemplos, la construcción masiva de hidroeléctricas, carreteras y aeropuertos, los monocultivos agroindustriales y la extracción mineral $y$ de combustibles fósiles a gran escala, intensificadas desde la década de 1970 y cuyo objetivo principal es expandir las fronteras del mercado. Según Carlos Loureiro:

Mientras más crecen los sectores industriales y de servicios en los llamados países centrales, más se demandan materias primas, producción agrícola, extracción mineral y producción de energía en los llamados países periféricos, [que son] escenarios de grandes programas de infraestructura y estímulo al agronegocio $y$ a la exportación con base en enormes sacrificios naturales $y$ humanos (2012: 23).

En esos casos, los espacios productivos privados transmiten los efectos nocivos de sus prácticas para el medio ambiente colectivo $y$ privan a amplios sectores de la población de hacer usufructo de los recursos naturales, haciéndolos así bienes escasos. Paradójicamente en la economía capitalista, los recursos son más valorizados cuando son escasos y tienen poco valor monetario cuando son abundantes (Porto-Gonçalves, 2011a). Ponerle un precio a los recursos es una forma de impedir que los 
otros tengan acceso a ellos, imponiendo no solo una forma única de producir sino una forma única de pensar, un "monocultivo de la mente", usando las palabras de la intelectual y activista india Vandana Shiva (Shiva, 2008).

En relación con la esfera del consumo, las cifras del Programa de las Naciones Unidas para el Desarrollo, citadas por Ascelrad, Mello y Bezerra, expresan la gran concentración de recursos y bienes en pocas manos: "se estima que el $20 \%$ de la población mundial consume entre el $70 \%$ y el $80 \%$ de los recursos del mundo. Son ese $20 \%$ que consumen $45 \%$ de toda la carne $y$ el pescado, $68 \%$ de toda la electricidad, $84 \%$ de todo el papel y que poseen $87 \%$ de todos los automóviles" (2009: 75). Pierde toda su fuerza el discurso neomalthusiano según el cual, los problemas ambientales y la escasez de recursos naturales se explican por el crecimiento poblacional, ya que no es la "población mundial" la que causa tal desequilibrio, sino el elevado patrón de consumo de algunos grupos en específico, localizados en determinados países, regiones o inclusive, en determinadas zonas de una ciudad.

No son la producción y el consumo en sí que generan tal presión, degradación y escasez, sino una determinada forma de producir $y$ de consumir. En palabras de Porto-Gonçalves:

... la preocupación con la explosión demográfica ya no se justifica más, a no ser como ideología. Todo parece indicar que en la expresión control de la población, la palabra clave es control y no población, porque no es la población que, en su número, está poniendo en riesgo al planeta y la humanidad (2011a: 164).

Existen diversos índices que refuerzan esta tesis. La huella ecológica, por ejemplo, calcula la cantidad de espacio que una población necesita $y$ utiliza para satisfacer una determinada forma de vida y nivel de consumo. Se estima a partir de cuatro variables principales: 1) la tierra usada para alimentar a una persona (que aumenta, por ejemplo, si se consume carne); 2) la tierra usada para producir madera para papel $y$ otros usos; 3) la tierra edificada y pavimentada para calles, carreteras, entre otros y 4) la tierra que serviría para producir la energía que cada persona consume (Martínez, 2004).

La huella ecológica es un índice que expresa una relación espacial y sus cifras ponen de manifiesto la desigualdad que existe en el acceso a los recursos ambientales. Por ejemplo, un estadounidense promedio, para mantener su nivel de consumo, demanda 12 veces más espacio que lo demandado en promedio por un habitante del continente africano, 6 veces más que un asiático y 2 veces más que un europeo norte-occidental (Porto-Gonçalves, 2011a). Visto desde otra perspectiva, países como Corea del Sur, Japón o países europeos densamente urbanizados, utilizan ecoespacios diez o quince veces mayores que sus propios territorios (Martínez, 2004).

La injusticia ambiental se manifiesta en múltiples escalas, no solo entre países. Dentro un mismo país o inclusive, en una misma ciudad, las asimetrías pueden ser igualmente marcadas. Contrario a lo que se podría esperar, la primera experiencia de un movimiento identificado con el nombre de justicia ambiental, que dio origen al término, se dio en los Estados Unidos, específicamente, en el Estado de Carolina del Norte, en la década de 1980. Esta nueva concepción del ambiente como una cuestión de justicia social permitió por primera vez en ese país, el acercamiento del Movimiento Negro con el Movimiento Ambientalista, el cual siempre estuvo más enfocado en la preservación y el "culto a lo silvestre" (Martínez, 2004).

Como resultado de una articulación creativa de luchas de carácter social, ambiental y por derechos civiles, se incluyeron dentro de las preocupaciones ambientales, las condiciones inadecuadas de saneamiento básico, de contaminación química de los lugares de habitación y trabajo, así como, la descarga indebida de desechos tóxicos y peligrosos. Según denunciaron en aquel momento, esas actividades altamente contaminantes $y$ de riesgo para la salud, se concentraban principalmente, en los barrios más pobres, habitados en su mayoría por poblaciones negras y latinas, que a su vez eran las áreas con el precio de la tierra más bajo (Ascelrad, Mello y Bezerra, 2009). 
Lo que los movimientos por justicia ambiental han demostrado, es que la escogencia de tales lugares no es aleatoria, sino motivada por características socioeconómicas y raciales de la población. La lucha llevada a cabo en 1982, en Afton, Carolina del Norte, contra la instalación de un depósito de policlorinato de bifenil que amenazaba contaminar el abastecimiento de agua de la ciudad, desencadenó una serie de movilizaciones, reflexiones y estudios acerca de las relaciones entre injusticia social y el medio ambiente. En 1987, la United Church of Christ realizó una investigación junto con el sociólogo Robert Bullard, en la cual se llegó a la conclusión de que la variable "raza" era la que más peso tenía al momento de explicar la presencia 0 ausencia de un depósito de materiales peligrosos en un lugar, inclusive por encima de la variable "bajo ingreso". Fue en ese instante que el reverendo Benjamin Chavis acuñó la expresión racismo ambiental (Porto-Gonçalves, 2011a; Ascelrad, Mello y Bezerra, 2009).

Contra la naturalización de tales injusticias, los movimientos por justicia ambiental han colocado en debate público y han denunciado toda una lógica sociopolítica que promueve $y$ reproduce las desigualdades ambientales. Alrededor del mundo, innumerables son las movilizaciones de grupos de base comunitaria (muchas veces con el apoyo de organizaciones ambientalistas internacionales) que han pautado sus reivindicaciones desde los principios $y$ las estrategias de la justicia ambiental. El catalán Joan Martínez Alier, en su libro El ecologismo de los pobres (2004) relata con detalles, diversos casos de luchas ambientales protagonizadas desde los sectores populares, principalmente, en países del llamado Tercer Mundo.

Un aspecto en específico que merece atención, es la crítica hecha desde estos movimientos hacia los llamados estudios o evaluaciones de impacto ambiental (EIAs), los cuales, más que una evaluación de los posibles impactos de proyectos de desarrollo y actividades productivas, muchas veces funcionan para legitimar $y$ justificar tales proyectos a cualquier costo. Por lo general, tales estudios separan el medio ambiente de sus dimensiones sociopolíticas y culturales, configurando una especie de industria de EIAs (Ascelrad,
Mello y Bezerra, 2009). Se clama por una mayor participación de las poblaciones locales y la sociedad civil en la toma de decisiones sobre cuestiones ambientales, sobre todo si les afectan directamente: "aquello que los trabajadores, grupos étnicos y comunidades residenciales saben sobre sus ambientes debe ser visto como parte del conocimiento relevante para la elaboración no discriminatoria de políticas ambientales" (Ascelrad, s.f.: 3-4).

\section{NO TODO LO “VERDE" ES AMBIENTALMENTE JUSTO}

El ambientalismo como una corriente políticamente definida surge a partir de relaciones sociales $y$ de poder contradictorias $y$ en crisis. Justo ahí donde el modelo capitalista de acumulación había parecido salir victorioso, donde se tiene mayor poder de consumo y más comodidades, en Estados Unidos y Europa Occidental, fue desde donde se hicieron serios cuestionamientos a todo ese modelo civilizatorio, principalmente desde la década de 1960. Solo se puede producir $y$ ofrecer ciertos bienes considerados esenciales para el confort moderno a partir de relaciones sociales desiguales. Solo se puede considerar como legítimos ciertos estilos de vida cuando se ignora la indigencia de millones y además, basado en el uso abusivo e insostenible de los recursos naturales (Loureiro, 2012). El planeta ya no era más una fuente inagotable de recursos.

Por su parte, en aquella época, en el polo subalterno del sistema-mundo, los países del Sur o del Tercer Mundo, ganaba mucha fuerza la conciencia del subdesarrollo, es decir, la otra cara del desarrollo, la que paga a un precio muy alto los privilegios del Norte. Ese momento coincide con la insurgencia de varios movimientos de descolonización, sobre todo en África y Asia, asî como con levantamientos populares de izquierda en todos los continentes. En el marco de la sociedad capitalista urbano-industrial, la sustentabilidad de la riqueza necesariamente trae su inverso, la sustentabilidad de la pobreza (idem.).

La insurgencia del movimiento ecológico, al proponer otra relación de los seres humanos con la naturaleza, describe también otras relaciones entre los seres humanos, otra cultura, otros valores (Porto-Gonçalves, 2011b). 
En sus orígenes lo que el ambientalismo coloca como el principal problema a ser superado es justamente lo que el paradigma del progreso y el desarrollo propone como solución e ideal a seguir: la idea de dominación y explotación de la naturaleza. Al final "desarrollo" significa separarse de la naturaleza, para así dominarla (para poder dominar primero hay que colocarse jerárquicamente en una posición superior). Los "desarrollados" son los más urbanizados, los más industrializados, los que poseen más tecnología y los que más se han alejado de la naturaleza (Porto-Gonçalves, 2011a).

Al mismo tiempo, esa dominación no es solo de la naturaleza, es también de aquellos pueblos y culturas que viven según otras formas, no hegemónicas. Entre esas miles de culturas diversas que la humanidad ha creado a lo largo de su historia, una característica que probablemente sea común para la gran mayoría de estas, sea la condición de vivir y posicionarse en la naturaleza y no contra ella. El paradigma civilizatorio del desarrollo y la modernidad se fundamentan en relaciones de subordinación y explotación tanto hacia la naturaleza como hacia culturas diferentes; todo puede ser una mercancía. Asimismo, el ambiente se constituye a través de relaciones de poder, en este caso, desiguales.

Ese enfrentamiento contradictorio está muy presente hoy, donde muchas veces los grupos ambientalistas y las poblaciones locales son acusados de ir contra el desarrollo por oponerse a la construcción de represas hidroeléctricas y grandes carreteras, a la sustitución de bosques $y$ tierras comunes por monocultivos, a la expulsión de sus territorios ancestrales, a la privatización del agua, a la contaminación de las grandes industrias, entre otros. Parece que el desarrollo, más que una opción para las sociedades, un posible camino, es una obligación y una imposición (idem.). En realidad, ir contra el desarrollo o estar fuera de este no es necesariamente algo malo, existen otras alternativas de vida que por lo menos deberían ser respetadas y escuchadas.

El origen de los movimientos ambientalistas de contracultura trae consigo esa crítica radical a la propia noción de desarrollo. Sin embargo, algunos sectores dentro del campo ambiental han renunciado a esa raíz crítica de justicia social $y$ de una forma $u$ otra han ajustado las luchas en defensa del medio ambiente para que estas no alteren las formas históricamente consolidadas de concentración del poder. Se puede hacer una analogía con la famosa frase del teólogo de la liberación Dom Helder Câmara, quien dice que cuando alimentó a los pobres lo llamaron santo, pero cuando preguntó por qué hay gente pobre lo llamaron comunista ${ }^{1}$. Además, ese viraje acrítico presenta una característica fundamental del pensamiento eurocéntrico: la separación entre sociedad y naturaleza. Los problemas ambientales son abstraídos de su origen socialmente constituido.

Para continuar con el ejemplo anterior, por lo general para explicar el hambre se habla de cambio climático o de sequías, pero poco se cuestiona, por ejemplo, la desigualdad en el acceso a la tierra, el latifundio y actualmente, el agro-negocio, que impide a millones de familias producir sus alimentos $y$ tener un lugar donde vivir.

La homogenización en la agricultura en todo sentido genera vulnerabilidad. Por un lado, desplaza a las poblaciones locales de sus tierras, cortando profundos vínculos históricos con el territorio y sustituyendo bosques $y$ agroecosistemas diversos por monocultivos dependientes de insumos externos. Es claro que un cultivo de una sola especie no garantiza la seguridad alimentaria, su razón de ser es comercial y además, la producción no está destinada para quienes son del lugar. Por otro lado, hay una tendencia a que los conocimientos patrimoniales y comunitarios sobre las especies cultivadas, finamente adaptadas a cada ambiente, pasen a ser propiedad privada intelectual (patentes) de grandes corporaciones. Así, la seguridad alimentaria es desplazada por la lógica mercantil.

1 Esta frase de Dom Helder Câmara ha sido ampliamente conocida $y$ difundida por diversos medios, sobre todo en Internet. No se consigue encontrar cuál fue el contexto original donde fueron expresadas tales palabras; sin embargo, lo más importante es destacar que la transición del acto de alimentar a los pobres a preguntar por qué son pobres, es el mismo movimiento que va de la caridad a la justicia (Losada, 1999). Esa crítica radical a una determinada organización social hegemónica está a la orden del día con las luchas que se traban en diversas partes del mundo por justicia ambiental. 
Paradójicamente, se denominó de revolución "verde" a ese conjunto de transformaciones en el mundo rural, con el protagonismo cada vez mayor de la alta tecnología, las industrias y el componente técnico-científico en la producción (idem.).

Lo ambiental ha sido exitosamente apropiado por el lenguaje del mercado y el paradigma de la modernidad y el progreso. Surgen intentos de conciliar crecimiento económico con sustentabilidad ecológica, apoyados en conceptos como "ecodesarrollo", "modernización ecológica" y el famoso "desarrollo sostenible", que surgió por primera vez en 1983, en el Informe Nuestro Futuro Común de la Comisión Mundial de Medio Ambiente y Desarrollo de la onu (conocido también como Informe Brundtland), y se formalizó como concepto en 1987, cuando dicho documento fue aprobado (Loureiro, 2012). De nuevo, se ofrece como solución más desarrollo, consolidando así un pensamiento ecológico dominante en los medios políticos, empresariales y en las agencias multilaterales.

Principalmente, desde la década de 1970, se vive una situación paradójica, donde por un lado, nunca ha habido tanta discusión y consideración por las cuestiones ambientales como en ese período y por otro, nunca ha sido tan intensa la devastación del medio ambiente. El papel de organismos multilaterales como el Banco Mundial ha sido determinante, a través del financiamiento para la construcción de grandes emprendimientos $y$ obras de infraestructura, sobre todo en los países del Tercer Mundo. Como se mencionó anteriormente, la construcción de hidroeléctricas y grandes carreteras, así como, la extracción mineral para la industria y los monocultivos de la revolución verde, han permitido la expansión de las fronteras del mercado, estimulados por tales organismos.

Como muestra el geógrafo brasileño Carlos Walter Porto-Gonçalves, en respuesta a las críticas de diversos grupos ambientalistas y la sociedad en general, tales organismos multilaterales $y$ el sector empresarial dominante han diseñado su propio orden ambiental, dentro de una geopolítica del neoliberalismo ambiental:

Se trata de una visión que defiende que el mercado, si operado libremente, es el único medio concebible de alcanzar el desarrollo sostenible, expresión que cada vez más está dentro del mainstream. Ahí, se asume que los agentes principales de tal transición para un mundo más sustentable deberían ser las corporaciones multinacionales, las cuales supuestamente extenderían principios de administración de total calidad y fijación de precios de acuerdo con los costos para acompañar las preocupaciones ambientales.

Así, ante los avances de múltiples movimientos sociales que lograron imprimir al debate [ambiental] un fuerte carácter social $y$ de respeto a la diversidad cultural, se desencadenó una amplia estrategia empresarial con la ayuda de grandes organizaciones no gubernamentales, para que se condicionara la busca de alternativas políticas a los marcos del orden social existente, o sea, que se adaptasen las soluciones a los marcos del mercado, a las reglas de juego del capitalismo; en fin, se procuraba retirar la iniciativa de aquel protagonismo de amplia base popular y cultural, defendiendo que el mercado es la única solución posible para cualquier problema, inclusive los ambientales (2011a: 302).

Esta frase deja en evidencia las fuertes disputas que existen dentro del campo ambiental, el cual ha dejado de ser exclusivo de los ambientalistas y ha permeado tanto para "abajo"; es decir, los sectores populares y poblaciones tradicionales, como para "arriba", el capital financiero y transnacional. Se trata de un campo realmente estratégico y en este proceso creciente de mercantilización del medio ambiente que se ha buscado censurar y desviar la atención del carácter cultural y político del debate ambiental para así presentarlo como un asunto estrictamente técnico, del cual las empresas se harían responsables. También se comparten las palabras pertinentes de Ascelrad, Mello y Bezerra:

El término "modernización ecológica" se ha hecho conocido por designar una serie de estrategias de corte neoliberal para el 
enfrentamiento de los desequilibrios ecológicos sin considerar su articulación con la cuestión de la desigualdad social. La estrategia de la modernización ecológica es aquella que propone conciliar el crecimiento económico con la solución de los problemas ambientales, dando énfasis a la adaptación tecnológica, a la celebración de la economía de mercado, a la creencia en la colaboración y el consenso. Además de legitimar el libre mercado como el mejor instrumento para resolver los problemas ambientales, esta concepción procuró hacer del medio ambiente una razón más para implementar el programa de reformas liberales (2009: 14).

Martínez (2004) identifica tres corrientes principales dentro del ambientalismo:

1) El "culto a lo silvestre" es aquella corriente preocupada en la preservación de la naturaleza, siendo su principal propuesta política, la creación de reservas naturales o parques nacionales fuera de la interferencia humana; puede admitir visitantes pero no habitantes. Además, el culto a lo silvestre no ataca el crecimiento económico, admite la derrota ante este y lo que asume es una acción de retaguardia para proteger los espacios naturales que quedan fuera del mercado. Esta corriente proviene sobre todo de los países industrializados, a través de organismos consolidados como International Union for the Conservation of Nature (IucN), World Wide Fund for Nature (wwF) y Nature Conservancy (idem.). Para esta corriente la conservación de la naturaleza es un lujo y una fuente de ocio antes que una necesidad para la sobrevivencia cotidiana. Detrás de la creación de muchos parques nacionales hay un conflicto social, debido al desplazamiento forzado de poblaciones $o$ a las restricciones $y$ prohibiciones, en cuanto al uso de recursos naturales.

2) El "evangelio de la ecoeficiencia" se inscribe dentro de lo que se denomina líneas atrás de neoliberalismo ambiental. "Los representantes de esta segunda corriente apenas utilizan la palabra naturaleza, más bien hablan de recursos naturales o hasta de capital natural o servicios ambientales" (idem.: 20). Corresponde a una visión utilitarista $y$ de eficiencia técnica, de un "uso racional" de los recursos que busca soluciones de ganancia económica y ganancia ecológica (win-win), dentro de ese vínculo empresarial con el desarrollo sostenible. Esta corriente respaldada por disciplinas como la ecología industrial y la economía ambiental, sostiene que las nuevas tecnologías son instrumentos decisivos de la modernización ecológica.

3) La "justicia ambiental" y el "ecologismo de los pobres", dentro de la que se enmarca este artículo. En realidad, dicen los ecologistas populares, el crecimiento económico implica mayores impactos sobre el medio ambiente $y$ tales impactos son desigualmente distribuidos. Hay una incompatibilidad de fondo entre el crecimiento ilimitado al que el mercado capitalista aspira y cualquier noción de sustentabilidad, por el simple hecho de que el ritmo de extracción de recursos es mucho mayor al de su regeneración natural. Además, los "recursos" no son solamente naturales, sino que de ellos dependen $y$ se interrelacionan culturas, conocimientos, estilos de vida y (otras) formas de producción.

Lo que ocurre es que las fronteras espaciales del mercado se desplazan constantemente, es decir, se abandona el lugar donde se agotó la fuente de algún recurso para explotar en otro (inclusive, a través de guerras) o bien, se instala un nuevo lugar para la deposición de desechos (sumideros de residuos). Desde este punto de vista, la economía puede crecer "ilimitadamente", siempre y cuando los grupos más vulnerados, sus recursos y territorios sustenten $y$ paguen el precio por tal ritmo: "mientras los males ambientales puedan ser transferidos para los más pobres, la presión general sobre el 
ambiente no cesará" (Ascelrad, Mello y Bezerra, 2009). Los problemas derivados de esa distribución desigual de provechos y desechos se conocen como "conflictos ambientales distributivos" y constituyen la principal área de interés de la ecología política.

Para el ecologismo popular, la preocupación por el medio ambiente es principalmente, por las posibilidades de sustento concreto $y$ material que este provee para la supervivencia del día a día. Su ética nace de una demanda de justicia social contemporánea entre seres humanos (Martínez, 2004). Alrededor de la justicia ambiental han confluido diversos grupos $y$ sectores, conformando un verdadero diálogo de saberes, entre la ciencia formal y la informal, entre lo local y lo global, recuperando saberes y prácticas tradicionales de la agroecología indígena y campesina para los desafíos ambientales contemporáneos (idem.).

Muchos de quienes practican el ecologismo popular no se hacen llamar ecologistas o ambientalistas, son simplemente miembros de grupos o comunidades en defensa del agua, del acceso a los bosques, contra la contaminación de sus tierras por agentes externos, etc. que defendiendo el ambiente, defienden una cultura. A pesar de haber sido estudiado y conocido con ese nombre apenas desde la década de 1980, el ecologismo de los pobres como un fenómeno real, ha existido durante mucho tiempo. $\mathrm{Mu}$ chos conflictos sociales ocurridos en el pasado pueden ser vistos retrospectivamente como conflictos ambientales, que fueron enfrentados desde un ambientalismo popular. Esta corriente diversa crece a nivel mundial, sobre todo en los países del Tercer Mundo, como consecuencia del número creciente de conflictos ambientales distributivos.

\section{JUSTICIA AMBIENTAL, CONFLICTOS Y TERRITORIALIDADES}

El ambiente no es algo ajeno o lejano al día a día de las personas. Lo que los conflictos ambientales distributivos ponen en evidencia es que las sociedades humanas solamente existen cuando las insertas materialmente en la tierra. Contrario a lo que muchos dicen, el mundo no se está desmaterializando o "virtualizando", lo cual es demostrado por el interés de las grandes corporaciones por el agua, bosques, minerales, suelos, biodiversidad y saberes ancestrales de los países tropicales.

También lo demuestra la respuesta de los pueblos alrededor del mundo, que resisten ante tales embates (independientemente, si salen victoriosos o derrotados), con el fin de poder hacer usufructo de sus tierras y recursos para vivir y sobrevivir. Se observa el carácter político de los conflictos ambientales, puesto que se trata del poder de unos $y$ otros para definir el destino de los recursos. La lucha de "los de abajo" es justamente para instituirse como sujetos de sus propios ambientes.

Ahora bien, los sujetos que protagonizan los conflictos ambientales usualmente no están en igualdad de condiciones. Existe un desbalance de fuerzas, que por lo general es naturalizado; esto hace prácticamente imposible que haya una negociación justa entre actores entre los cuales existen abismales diferencias de poder. Lo que se ha llamado "resolución negociada de conflictos" por lo general, busca eliminar el conflicto pero no el problema y no reconoce las diferencias reales entre actores y proyectos sociopolíticos y territoriales que deberían ser discutidos en la esfera pública.

Cuando envuelve actores con una marcada desigualdad de poder, esa resolución negociada puede funcionar como una tecnología de desmovilización social (Ascelrad, Mello y Bezerra, 2009). Muchas veces la discusión alrededor de un conflicto ambiental es colocada como si se tratase de un conflicto de intereses particulares entre dos o más grupos y se deja de ver la cuestión de fondo: en realidad se trata de disputas que involucran derechos (Svampa, 2008).

No todo puede ser resumido en términos de coste-beneficio, hay muchos otros lenguajes de valoración (Martínez, 2004) para abordar los conflictos, muchas otras formas de ver las situaciones que van más allá de un análisis estrictamente económico. El conflicto no es lo mismo que problema y muchas veces el conflicto $y$ la denuncia sirven para hacer visible un problema, dando el primer paso para superarlo. Como se observa, unos buscan eliminar o silenciar el conflicto; otros, superar el problema 
real. No sorprende el hecho de que cada vez más, se criminaliza la protesta ambiental, la cual deja en evidencia el carácter arbitrario y antidemocrático de los sentidos hegemónicos que son atribuidos al territorio (Zhouri y Laschefski, 2010).

La distribución de los recursos naturales por los diferentes lugares de la Tierra no es algo definido por los seres humanos. Lo que sí es definido social y políticamente es el acceso a tales recursos, el uso que se hace de ellos y el poder de definir el destino de los mismos. Es ahí donde se traban intensas disputas por el acceso y la gestión de los recursos, dándole al ambiente un marcado componente político, a través de la materialidad del territorio (Porto-Gonçalves, 2011a).

Una de las características de la territorialidad capitalista es justamente retirar (desplazar) recursos y riquezas de los lugares y así retirar el poder de "los del lugar" de decidir qué hacer con ellos (idem.). Es una apropiación que implica una expropiación y en el momento en que las poblaciones son separadas de las condiciones naturales de existencia, necesarias para la sobrevivencia, entonces se hace necesario vender la fuerza de trabajo y ser compradores de mercaderías (idem.), aquí se entiende, por ejemplo, la lógica de un monocultivo. El monocultivo solamente tiene sentido cuando el producto está destinado para afuera del lugar de producción y ser cambiado por dinero. Ningún grupo humano podría sobrevivir consumiendo únicamente caña, piña, banano o eucalipto; es un ejemplo más de injusticia ambiental, de un intercambio desigual de energía y trabajo.

En pocas palabras, se entiende la "territorialidad" como el proceso y el ejercicio del poder de los actores sociales en un espacio determinado (Georaizal, s.f.). En realidad es más preciso hablar de "territorialidades" antes que de territorialidad. Distintos actores tienen distintas formas de construir el territorio, por lo general, sobrepuestas espacialmente. Tal superposición no necesariamente significa que haya conflicto, aunque muchas veces así lo sea. Los conflictos se generan y agudizan cuando se niega esta complejidad y se pretende imponer una concepción territorial sobre las demás. Ahí la diferencia entre apropiación/uso $y$ dominación/control del territorio: la primera busca la reproducción de la vida, mientras que la segunda busca la reproducción del poder político, el capital y el control social (idem.). La dominación, al apropiarse, expropia; la simple apropiación y uso no necesita expropiar a nadie.

Se puede, una vez más, inspirarse en Porto-Gonçalves, quien hace una crítica a la concepción clásica de territorio, aquella restringida al territorio de los Estados-Nación y concebida como un ente pasivo, una base inmóvil sobre la cual se levanta la sociedad y el Estado. A su vez, esa visión estrecha todas aquellas territorialidades diversas y dinámicas que existen dentro de cada país y más allá de sus fronteras, oprimiendo también las diferentes formas que existen de ejercer el poder y existir culturalmente. Los territorios son siempre creaciones de sujetos históricos que, creándolos, se crean a sí mismos.

Sociedad $y$ territorio, vemos, son indisociables. Toda sociedad al constituirse lo hace constituyendo su espacio, su hábitat, su territorio. Al contrario del pensamiento disyuntivo que opera por dicotomías, como quiere hacer creer el todavía hegemónico pensamiento eurocéntrico moderno, no tenemos primero la sociedad (o el espacio) y después el espacio (o la sociedad)-sociedad $y$ espacio. En realidad, sociedad es espacio, antes de todo, porque es constituida por hombres $y$ mujeres de carne $y$ hueso que en su materialidad corporal no pueden prescindir del agua, de la tierra, del aire y del fuego (2006: 163).

Más allá de los territorios de dominación, mutuamente excluyentes, como lo son los Estados-Nación y la propiedad privada, por ejemplo, las situaciones que se están viviendo obligan a pensar en formas alternativas de crear territorio, formas alternativas de vivir en sociedad $y$ hacer uso de los recursos naturales.

En esa tensión de territorialidades, lo colectivo/comunitario se coloca casi siempre contrario a la exclusividad de 
la propiedad privada que, siendo espacio de uso exclusivo es, ya ahí, de exclusión; es la base del espacio mutuamente excluyente, de la soberanía absoluta que subyace al concepto de territorio en las matrices hegemónicas del pensamiento moderno-colonial. Así, es necesario superar esa lógica dicotómica, la lógica de esto o aquello $y$, definitivamente, aceptemos las lógicas relacionales, plurales y que nos apunten para territorialidades de otro tipo (idem.: 176).

Para finalizar este apartado, se hace referencia a un caso emblemático de ambientalismo popular y construcción de una territorialidad emancipadora. Este se llevó (y se lleva) a cabo en la Amazonia brasileña, en el Estado de Acre, fronterizo con Perú y Bolivia. Ahí, no solamente los grupos indígenas viven de la recolección de productos del bosque, sino también los seringueiros, que son descendientes de inmigrantes de la región noreste de ese país que llegaron a la Amazonia a trabajar en la extracción comercial del caucho desde las primeras décadas del siglo xx, en varias etapas. Después de varias décadas desde que la explotación a gran escala de ese producto acabara, estos grupos han tenido que encontrar sus propias formas de subsistencia y se han adaptado a la vida en el bosque tropical amazónico.

Durante las décadas de 1970 y 1980, como parte del proyecto desarrollista impulsado por la dictadura militar, se expandió la frontera agropecuaria hacia la Amazonia, abriendo una gran cantidad de caminos y carreteras, estimulando la llegada de colonos y empresarios a la región. Millones de hectáreas de bosque primario fueron transformadas en pastos para el ganado, en uno de los casos de deforestación más graves de la historia. También hubo fuertes cambios en la tenencia de las tierras, apropiadas y privatizadas masivamente por los ganaderos, en perjuicio de las poblaciones locales y sus formas de uso tradicionales.

En el Acre, los ganaderos adquirieron seis millones de hectáreas entre 1970 y 1975, desplazando a miles de familias de seringueiros (Martínez, 2004), un proceso además, altamente violento. Ante tal situación, los seringueiros recurrieron a una forma original de protesta $y$ resistencia pacífica que fue conocida como "empate". Hombres, mujeres y niños se tomaban de la mano de frente a los madereros y sus motosierras, para impedir la tala de árboles, fuente de su sustento.

Se conformaron varios sindicatos y en 1987, junto con organizaciones de pueblos indígenas amazónicos, dieron nacimiento a la Alianza de Pueblos del Bosque. Desde este espacio, se buscó defender los bosques y los derechos territoriales de sus habitantes. La perspectiva del ecologismo popular se expresa nítidamente en la lucha de los seringueiros cuando estos afirmaban que no podía existir defensa del bosque sin los pueblos del bosque.

Según Martínez: "trabajaron, con cierto éxito, no sólo en la demarcación de los territorios indígenas tradicionales para que estos sean excluidos de la privatización y los cerramientos; sino en la creación de nuevas formas de posesión comunitaria, llamadas reservas extractivistas" (idem.: 164; cursiva propia). En las reservas extractivistas, los seringueiros pueden producir y cosechar lo que necesitan para el sustento y el mercado, sin poner en riesgo los ritmos de regeneración del bosque, como siempre lo han hecho. Necesitan del bosque para reproducirse $y$ dar continuidad a un modo de vida propio. Es un caso realmente innovador y ejemplo real de sustentabilidad, en palabras de Martínez, se trata de "una nueva construcción de instituciones para el manejo de recursos naturales (...) la invención de una nueva tradición comunitaria en medio de la Amazonia por grupos no indígenas" (Idem.).

Cuando la lucha de los seringueiros comenzó a ser reconocida internacionalmente y atraer activistas ambientales de todo el mundo, estos mismos decían que no había mayores ambientalistas que los seringueiros, palabra que a sus propios protagonistas les era desconocida. Actualmente, existen de tres a cuatro millones de hectáreas de reservas extractivistas demarcadas, dejando claro que el bosque en pie es la mejor opción, ambiental, social y económicamente. El precio por tal logro ha sido alto: mucho sufrimiento, persecución y decenas de 
asesinatos perdidos en la impunidad, como el caso famoso de Chico Mendes en 1988, líder de este movimiento. Para Mendes la reserva extractivista era la forma de los seringueiros de hacer su propia reforma agraria. Como se observa, los territorios se reinventan al calor de los desafíos diarios, cada uno a la medida de su contexto específico.

\section{CONCLUSIÓN}

La temática discutida en este texto es amplia $y$ diversa, $y$ ha sido abordada de una forma bastante general. Así, a través de este artículo se pretende aportar un punto de vista renovado y renovador, despertar inquietudes $y$ estimular otras investigaciones $y$ trabajos, tal vez profundizando más en algunos aspectos brevemente discutidos aquí, sea el tema de la seguridad alimentaria, la conservación, las políticas ambientales, el tema energético, los conflictos ambientales, las territorialidades plurales, entre otros. No se desestima el sueño de hacer ciencia para el bien común.

Varias ideas en íntima relación se encuentran presentes a lo largo de estas líneas. Como bien enseñan todos aquellos y aquellas que dedican su vida a la justicia ambiental, los seres humanos no somos algo aparte en la tierra. Nuestro origen es aquí y nuestro destino también. La Tierra es nuestro lugar. Solamente podemos vivir en relación e intercambio permanente con lo que es diferente (que en el fondo nos compone): agua, aire, plantas, animales, fuego, sol. Esto no niega el hecho de que tenemos características que nos hacen diferentes a cualquier otra especie, sobre todo nuestra capacidad de transformar el ambiente donde vivimos.

Como sujetos conscientes y responsables de nuestras propias decisiones, esa gran capacidad de transformar se ha convertido en una verdadera tragedia. El estilo de desarrollo predominante, que provee ventajas y comodidades para unos, realmente provoca condiciones de vida, insoportables e inhumanas para la mayoría. Esto ocurre justamente porque corta los vínculos que cada grupo tiene con sus ambientes, los cuales son fuente de vida y al hacerlo, corta los vínculos entre las personas. Como se comentó, solo se puede existir en relación con lo que es diferente y esto incluye también a los seres humanos que son diferentes.

Es fácil y cómodo decir que quiere un mundo donde todos vivamos bien. El desafío es posicionarse en las situaciones reales y concretas que se viven hoy $y$ desde ahí intentar construir ese mundo. Eso implica deconstruir mucho de lo que se ha construido y también construir lo nuevo desde lo que ha sido destruido. Implica ver de frente lo que no está funcionando bien. Para no caer en la trampa de pensar que un día todo se solucionará, es mejor estar anuente a la idea de que es un camino sin fin, una transformación permanente con desafíos nuevos constantes.

\section{BIBLIOGRAFÍA}

LIBROS

Ascelrad, Henri; Mello, Cecilia y Bezerra, Gustavo. O que é Justiça Ambiental. Rio de Janeiro, Brasil: Garamond, 2009.

Loureiro, Carlos Frederico. Sustentabilidade e Educação. Um olhar da ecologia política. São Paulo, Brasil: Cortez, 2012.

Martínez Alier, Joan. El ecologismo de los pobres. Conflictos ambientales $y$ lenguajes de valoración. Barcelona, España: Icaria, 2004.

Porto-Gonçalves, Carlos Walter. "A reinvenção dos territórios: a experiência latinoamericana e caribenha". Los desafíos de las emancipaciones en un contexto militarizado. Ana Esther Ceceña (comp.). Buenos Aires, Argentina. Consejo Latinoamericano de Ciencias SocialesCLACso, 2006: 151-197.

Porto-Gonçalves, Carlos Walter (2006). A globalização da natureza e a natureza da globalização. $2^{\text {a }}$ edición. Rio de Janeiro, Brasil: Civilização Brasileira, 2011a.

Porto-Gonçalves, Carlos Walter (1989). Os (des) caminhos do meio ambiente. $15^{\mathrm{a}}$ edición. São Paulo, Brasil: Contexto, 2011b.

Shiva, Vandana. Los monocultivos de la mente. Madrid, España: Fineo, 2008. 


\section{TEXTOS ELECTRÓNICOS}

Ascelrad, Henri. Justiça Ambiental. Novas articulações entre meio ambiente e democracia s.f. En: <http://www. justicaambiental.org.br/projetos/ clientes/noar/noar/UserFiles/17/ File/ JanovasArticulacoes-\%20ms.pdf> [consultado el 10 de agosto de 2013].

GeoRaizAL-Red de Geografía Crítica de Raíz Latinoamericana. Metodología para diagnóstico y análisis de conflictos territoriales s.f. En: < http:// www. georaizal.com/ georaizal/documentosde-trabajo/> [consultado el 2 de octubre de 2013].

Losada, Manuel. Hélder, Don y Profecía. 1999. En: <http://www.eurosur.org/acc/html/ revista/r37/37hpro.htm> [consultado el 13 de octubre de 2013].

Svampa, Maristella. Los nuevos conflictos territoriales: el escamoteo de la cuestión. 2008. En: <http://www.cetri.be/spip. php?article562> [consultado el 20 de setiembre de 2013].

Zhouri, Andréa y Laschefski, Klémens. Conflitos ambientais. 2010. En: <http:// conflitosambientaismg.lcc.ufmg.br/ wp-content/uploads/2014/04/zHOUR___ LASCHEFsK__Conflitos_Ambientais.pdf [consultado el 15 de agosto de 2013].

Fecha de ingreso: 28/10/2013 Fecha de aprobación: 17/02/2014 
